\title{
O audiovisual jornalístico da TV Pública nas mídias sociais: possibilidades e desafios para a divulgação científica
}

\section{Public television's audiovisual journalism in social media: possibilities and challenges for science communication}

\author{
Vanessa Matos Santos ${ }^{1}$, Carolina Rodrigues Oliveira ${ }^{2}$, Cindy Figueiredo Freitas ${ }^{3}$ e Valquíria Vieira ${ }^{4}$ \\ ${ }^{1}$ Universidade Federal de Uberlândia (UFU), Uberlândia, Brasil. ORCID: https://orcid.org/0000-0003-1041-367X \\ 2 Universidade Federal de Uberlândia (UFU), Uberlândia, Brasil. ORCID: https://orcid.org/0000-0002-1419-1691 \\ 3 Universidade Federal de Uberlândia (UFU), Uberlândia, Brasil. ORCID: https://orcid.org/0000-0001-5196-676X \\ ${ }^{4}$ Universidade Federal de Uberlândia (UFU), Uberlândia, Brasil. ORCID: https://orcid.org/0000-0002-0394-6147
}

Autor para correspondência/Mail to: Vanessa Matos Santos, vanmatos.santos@gmail.com

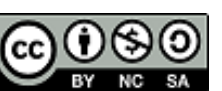

Copyright (c) 2019 Santos, Oliveira, Freitas \& Vieira. Todo o conteúdo da Revista (incluindo-se instruções, política editorial e modelos) está sob uma licença Creative Commons Atribuição-NãoComercial-Compartilhalgual 3.0 Não Adaptada. Ao serem publicados por esta Revista, os artigos são de livre uso em ambientes educacionais, de pesquisa e não comerciais, com atribuição de autoria obrigatória. Mais informações em http://revistas.ufpr.br/atoz/about/submissions\#copyrightNotice.

\begin{abstract}
Resumo
Introdução: O cenário de convergência tecnológica impõe desafios e, ao mesmo tempo, abre possibilidades de disponibilização de conteúdo jornalístico para públicos diversos. Destacam-se, neste cenário, as mídias sociais como novos espaços de prática jornalística por parte das TVs públicas no Brasil.

Objetivos: Nesse sentido, a análise aqui apresentada focaliza o caso da TV Universitária da Fundação Rádio e Televisão Universitária de Uberlândia.

Metodologia: Monitoramento realizado no Facebook da emissora para seleção e posterior análise de três reportagens com o respaldo metodológico do endereçamento.

Resultados: embora ainda não exista um formato audiovisual específico para mídias sociais, a disseminação de conteúdos por meio destes espaços configura-se como uma nova estratégia divulgação científica e jornalística para públicos cada vez mais heterogêneos.
\end{abstract}

Palavras-chave: Televisão pública; Audiovisual; Mídias sociais; Divulgação científica.

\begin{abstract}
Introduction: The technological convergence scenario poses challenges and, at the same time, opens up possibilities for making journalistic content available to diverse audiences. In this scenario, social media stand out as new spaces for journalistic practice by public TVs in Brazil.

Objectives: In that sense, the analysis presented here focuses on the case of University TV from the Fundação Rádio e Televisão Universitária de Uberlândia.

Methodology: Monitoring carried out on the broadcaster's Facebook page for selection, and subsequent analysis, of three reports with the methodological support of the addressing.

Results: although there is still no specific audiovisual format for virtual social networks, the dissemination of content through these spaces are configured as a new strategy for scientific and journalistic dissemination to increasingly heterogeneous audiences.
\end{abstract}

Keywords: Public television; Audiovisual; Social media; Science Communication.

\section{INTRODUÇÃO}

Embora muitos autores defendam que o início da história da televisão no Brasil teve seu marco em 1950, com a inauguração da primeira emissora brasileira, a PRF-3 TV Difusora (posteriormente chamada TV Tupi de São Paulo), pelo jornalista e empresário Assis Chateaubriand - também proprietário dos Diários e Emissoras Associadas, considerados "o primeiro império de comunicação do país" (Paternostro, 2006, p. 28), há documentações que demonstram que a primeira transmissão televisiva propriamente dita ocorreu em 1948 na cidade de Juiz de Fora em Minas Gerais (Lins, 2015).

Inicialmente considerada um artigo de luxo - cuja característica se refletia numa programação primariamente erudita, a televisão só passou a ser produzida em larga escala a partir da década de 1960, após o surgimento do videotape, o equipamento que permitia gravar o conteúdo. Este fato proporcionou a racionalização da produção do conteúdo televisivo, e as emissoras então existentes (TV Excelsior, TV Paulista, TV Record, TV Rio e TV Tupi de São Paulo e do Rio de Janeiro) passaram a disputar entre si a audiência - que, gradativamente, estendeu-se para todo o Brasil a partir do eixo São Paulo - Rio. Ao tornar-se acessível às demais camadas sociais, a televisão passou a contar com uma gama maior de programação, singularmente mais popular, que visava atender às exigências do novo público agregado (Lima, Priolli, \& Machado, 1985).

A história da TV no Brasil se desenvolveu com base no potencial de vendas (e lucro) que a mídia expressava para seus patrocinadores (Jambeiro, 2012; Mattos, 2002). O telejornalismo em si não implica, necessariamente, em lucro: não por acaso, a veiculação de conteúdos noticiosos nas grades televisivas foi imposta pelo Código 
Brasileiro de Telecomunicações (Lei n. 4.117, 1962). É fato que muitas emissoras encontraram, com o tempo, formas de viabilizar financeiramente a produção telejornalística, mas que, não raro, terminavam por comprometer a isenção tão cara ao jornalismo em sua deontologia (Traquina, 2004). Nesse cenário, destaca-se, sobremaneira, a importância dos conteúdos produzidos pelas emissoras públicas de televisão e rádio pela liberdade em relação ao capital e por seu compromisso social.

Adota-se, no escopo deste artigo, a assunção de que "canais públicos são veículos de comunicação com independência financeira e administrativa do Poder Público", mas que representam interesses plurais da sociedade, não necessariamente alinhados aos do Estado (Nazareno, 2007, p. 5). Finalmente, esclarece-se que, dada a complexidade do objeto em estudo, foi preciso triangular os dados com duas diferentes metodologias: o monitoramento de mídias sociais (Altmetria) foi usado para conhecer o espaço virtual e compreender as dinâmicas sociais travadas a partir do contato com os materiais. Posteriormente, utilizou-se a metodologia de endereçamento com o objetivo de aprofundar a compreensão acerca dos conteúdos presentes nas reportagens. Aqui, é importante esclarecer que não houve produção específica para as mídias sociais: as reportagens foram postadas nas redes apenas após a exibição na televisão.

\section{REFERENCIAL TEÓRICO}

\section{TV Pública}

Uma das principais características da TV Pública no Brasil é a prioridade dada ao interesse público - que engloba aspectos relevantes para o social, evidenciando a sociedade, os indivíduos que a compõem, as necessidades sociais; enfim, valorizando o cidadão. A discussão passa a abordar mais um fato específico e as pessoas nele envolvidas do que da questão social que o cerca e o impacto dele em maior escala. O aspecto preponderantemente educativo do conteúdo audiovisual exibido pelas emissoras públicas também merece destaque. Não por acaso, muitas emissoras públicas são também chamadas educativas. Conforme o Decreto-Lei n. 236, de 28 de fevereiro de 1967, a televisão educativa se destina majoritariamente à "divulgação de programas educacionais, mediante a transmissão de aulas, conferências, palestras e debates", podendo ser executada pela União; Estados, territórios e municípios; universidades; e fundações constituídas no Brasil, em que os estatutos não se contraponham ao Código Brasileiro de Telecomunicações (Decreto-Lei n. 236, 1967).

Nesse rol devem ainda ser incluídas as TVs Universitárias: emissoras que se alinham a uma instituição de ensino superior (pública ou privada). A pioneira delas foi a TV Universitária (TVU) da Universidade Federal de Pernambuco (UFPE), a primeira a reunir condições técnicas e políticas para obter a primeira concessão de canal educativo no sistema VHF no Brasil (Prevedello, 2017).

Outras emissoras universitárias surgiram com o passar dos anos. A mesma autora esclarece que a TV Cultura e a TVE foram as emissoras âncora para complementação das grades nas emissoras universitárias nos anos 80 e 90 - que, em sua maioria, não dispunham de condições técnicas para preencher a totalidade de suas grades com conteúdo próprio de forma consistente. Gradativamente, as TVs universitárias foram se diferenciando e estabelecendo uma produção audiovisual autônoma. Isto posto, fica claro que é possível identificar as TVs universitárias vinculadas a instituições estatais como um dos segmentos potenciais para a democratização audiovisual no Brasil.

Em que pese a diversidade semântica e até mesmo sobreposição conceitual, é importante destacar que o termo TV Pública é o mais abrangente e capaz de abarcar as características das TVs do campo público no Brasil (Santos, Santos, Marinho Jr., \& Santos, 2016). Pieranti e Fernandes (2017) esclarecem que a radiodifusão educativa é o embrião da radiodifusão pública no Brasil - tanto que, o que se chama de radiodifusão pública é o conjunto de consignações da EBC que, antigamente, eram reconhecidas como outorgas de radiodifusão educativa. Além disso, a radiodifusão educativa pertence ao sistema público, pois nem sempre está vinculada ao Estado e não é explorada por emissoras comerciais.

Apesar de muitas emissoras com o foco voltado para a cultura e a educação já existirem (ex.: TV Escola (1995), TV Cultura (1960), entre outras), as diretrizes para implantação de um sistema propriamente dito de TV Pública no Brasil ocorreu apenas em 2007. Naquele ano, o I Fórum Nacional de Televisão Pública discutiu tais diretrizes, que acabaram por possibilitar a formatação de um projeto de sistema público de radiodifusão, a ser gerido pelo governo federal, culminando no surgimento da Empresa Brasil de Comunicação (EBC) e no lançamento da TV Brasil, em dezembro de 2007 (Stevanim, 2017). Hoje, muitas emissoras culturais, educativas e universitárias integram a rede de TV Pública no Brasil. Este processo, no entanto, apresenta-se de forma incompleta, pois a EBC depende de outorgas de parceiros para estruturar uma rede pública. Trata-se de um processo que requer convencimento, estratégias de operacionalização e, sobretudo (eis aqui o ponto nevrálgico) afinidade ideológica. Deve-se somar a este cenário também o aspecto financeiro: muitas emissoras educativas ainda não dispõem de infraestrutura mínima para produção de conteúdos digitais e estão ainda muito distantes do processo de digitalização (Pieranti \& Fernandes, 2017). 


\section{Produção jornalística da TV Pública}

As TVs Públicas desempenham papel informacional fundamental porque, ao não estarem à mercê das forças do mercado, têm - ao menos teoricamente - condições de oferecer uma informação mais qualificada. Outros requisitos que resultam em diferenciais de uma emissora pública são pontuados porBucci (2013): a natureza jurídica não está ligada ao Estado, e seu financiamento é de natureza pública, isto é, a emissora se mantém através de dotações regulares vindas do Estado ou da sociedade. Desta forma, mesmo quando recebe aporte financeiro do Estado, a emissora pública permanece independente, pois não está diretamente vinculada ou subordinada ao órgão. O fato de receber auxílio desta natureza não dá direitos de interferências na programação e no conteúdo transmitido.

Quanto à importância desempenhada pelas emissoras públicas de televisão e rádio no Brasil, muitas delas não conseguem estabelecer vínculo (que se traduza em audiência ativa) com o cidadão, justamente por não abrirem espaços para produções oriundas da sociedade civil. Não raro, as TVs Públicas tendem a reproduzir o mesmo modo de trabalho, formatos e estrutura das TVs privadas, fazendo com o que o cidadão não seja capaz de visualizá-las como espaços de exercício da cidadania ou ambientes de inovação e liberdade criativa.

$\mathrm{Na}$ contramão de sua proposta, frequentemente acabam vistas como TVs menores, ou ainda, com baixa qualidade e menos interessantes.Bucci (2013) ironiza ao afirmar que, ao insistir em copiar a televisão comercial, "a TV pública [...] ganha um ar de atração requentada, de espetáculo de segunda". Ao tentar estabelecer os mesmos "padrões estéticos" das emissoras comerciais, "acaba ficando insuportavelmente chata" (Bucci, 2013, p. 134). As televisões públicas são espaços para debater conteúdos que nem sempre estão na pauta de emissoras privadas, principalmente devido a pressões comerciais. São locais para o aprofundamento e compromisso com informação, cultura e educação, com conteúdo de qualidade (Carrato, 2013; Silva, 2016). Esses pontos devem ser os balizadores da produção informativa no telejornalismo de maneira geral e, ainda mais, quando o tema se desloca para a TV Pública. De qualquer forma, é salutar destacar os embates enfrentados pelo jornalismo na atualidade.

Gomes (2011) destaca a influência de duas questões centrais da contemporaneidade no jornalismo em âmbito profissional, ideológico e social, a saber: a tecnologia digital e o multiculturalismo, que favorecem a globalização. Para a autora, é fundamental "interrogar a conjunção entre jornalismo, sociedade e cultura, como essa conjunção interage com e reconfigura certos valores jornalísticos tomados como universais: interesse público, objetividade, atualidade, credibilidade, independência, legitimidade" (Gomes, 2011, p. 22).

Com base nessas cinco instituições básicas, retomamos a definição de Nazareno (2007) sobre a televisão pública: ela deve representar os interesses plurais da sociedade na qual está inserida, não necessariamente ligados aos do Estado. Dito isso, o telejornalismo neste contexto deve perpassar essas cinco instituições, por carregarem, em si, o potencial da diversidade, inerente a qualquer sociedade multicultural. Nesta linha, Gomes (2011) questiona se a diversidade cultural não implicaria numa modificação da noção de interesse público na sociedade, citando como exemplo o caso da imigração no continente europeu, que é um constante pretexto para várias disputas políticas. Entretanto, conforme a autora, tal situação implica também na redefinição do jornalismo em direção ao reconhecimento da identidade cultural nesses países, ou, minimamente, intensifica a crítica ao modo como os jornalistas e os veículos de comunicação enquadram a diferença cultural.

Gomes aponta também para a produção do "jornalismo cidadão", em que, especificamente no caso do telejornalismo, as emissoras têm incluído em seu rol de imagens aquelas feitas por amadores, particularmente através de telefones celulares. Estas imagens, conforme ressalta a autora, "não seguem quaisquer dos critérios profissionais de controle e verificação da informação - como modo justamente de ampliar a autenticidade e a veracidade dos programas telejornalísticos" (Gomes, 2011, p. 23). No Brasil, há um exemplo de telejornal na televisão pública que conta com a participação do telespectador, na sugestão de pautas: o STJ Notícias, da TV Justiça. Deve-se destacar que, embora a televisão pública no Brasil não siga os moldes internacionais - particularmente no que diz respeito à independência do Estado em termos financeiros e ideológicos -, a TV Justiça se enquadra nesta denominação, pois o canal tem propósito não lucrativo e pretende "preencher lacunas deixadas por emissoras comerciais em relação a notícias sobre questões judiciárias, a fim de possibilitar que o público acompanhe o cotidiano do Poder Judiciário e suas principais decisões" (TV Justiça, 2020¹).

O STJ Notícias - ou STJN - está no ar desde fevereiro de 2014, e foi o primeiro telejornal do judiciário brasileiro produzido para a Internet. Neste meio, através do Facebook e do WhatsApp, o público entra em contato com a equipe jornalística, sugerindo pautas e levantando questionamentos, que são respondidos em programas subsequentes. Destaca-se que "de modo geral, o paradigma de relacionamento com a sociedade no STJ leva muito em conta o cidadão e suas dúvidas sobre legislações e julgados que são direcionados a um dado magistrado ou gabinete" (Santana, Dias, Muniz, \& Gomes, 2017, p. 124), caracterizando o que os autores definem por stakeholder - ou público de interesse, que segue uma lógica de comunicação organizacional -, e não uma relação de público leitor, que consistiria na TV Justiça e o cidadão, juntos, pautando o conteúdo.

\footnotetext{
${ }^{1}$ Informações disponíveis no site oficial da emissora, disponível em: http://www.tvjustica.jus.br/index/conheca. Acesso em: 21 maio 2020.
} 
É importante destacar que, apesar da inovação apresentada pelo STJN, ainda é visível que não há a formação de uma audiência ativa (Meso, Agirreakzuenaga, \& Larrondo, 2015), ou seja, aquela que não apenas envia sugestões (que podem ser acatadas ou não, acatadas em partes, transformadas etc.), mas aquela que se coloca no programa por meio de conteúdos gerados por ela (e não apenas a partir dela). Não raro, o que ocorre é que normalmente as emissoras solicitam ao público o envio de materiais pautados. Exemplo claro disso é a recente campanha da Rede Globo intitulada "O Brasil que eu quero". Numa outra vertente, quando os materiais não assumem o tom propagandístico, o que se tem é o incentivo para que o público envie vídeos com flagrantes para exibição nos jornais sensacionalistas, corroborando uma "estética do flagrante" e fomentando a espetacularização (Bruno, 2006). Se as emissoras privadas ainda caminham timidamente para isso, as públicas estão ainda mais distantes em função de seu atraso tecnológico evidente quando comparadas com as primeiras.

Pode-se perceber, assim, que há pouco espaço para que o público efetivamente produza conteúdo noticioso televisivo. Mas, nem por isso o público deixa de expressar seus anseios, percepções, aprovações e desgostos. Os canais virtuais das emissoras (tais como Facebook e YouTube) acabam recebendo um retorno praticamente imediato a respeito da opinião do público com relação às exibições televisivas. Caracterizadas essencialmente pela instantaneidade, essas redes possibilitam um tipo de participação diferente: por meio delas, o cidadão pode fazer críticas e sugestões sem, necessariamente, passar por processos de edição de sua fala. É possível reclamar e disseminar um ponto de vista sem ter que sair da comodidade do espaço de sua casa.

Enquanto espaços virtuais que possibilitam a formação de laços sociais, as redes devem ser entendidas como elementos-chave na compreensão das dinâmicas que se estabelecem. Segundo Recuero (2009), estas dinâmicas podem ser compreendidas por meio do conceito de "valor social". A autora explica que o aspecto individual é definido por meio do interesse de cada pessoa em participar de uma rede social a fim de alcançar benefício próprio. O aspecto coletivo, por sua vez, é reflexo da esfera coletiva de um grupo a partir do capital social individual. Dessa forma, a autora define o capital social sob o amparo da pesquisa de Bourdieu (1983), que aponta três definições distintas de capital presente nos meios sociais: o econômico, o cultural e o social. Existe ainda o capital simbólico, que possibilita a legitimação 'de posse dos anteriores como um recurso.

A partir do entendimento de que, para o autor, o capital social está ligado aos "interesses individuais, no sentido de que provém de relações sociais que dão a determinado ator determinadas vantagens" (Bourdieu, 1983 como citado em Recuero, 2009, p. 45), Recuero argumenta que este é, portanto, um conceito-chave, pois que se configura como "um recurso fundamental para a conquista de interesses individuais" (Recuero, 2009. p. 45). A partir dessa discussão, Recuero $(2009,2012)$ sugere que o capital social deve ser recíproco, além de apresentar contínua adaptação por meio de suas funções. As pessoas não se despem de suas máscaras sociais para estar nestes locais; entretanto, a essência e os valores seguem os mesmos. Desta forma, embora Bourdieu não tenha se dedicado a estudar as mídias sociais, fica claro que a base de mundo social é válida para quaisquer espaços que se traduzam pelas dinâmicas sociais, posto que "Um mundo social é um universo de pressuposições: os jogos e os objetivos que ele propõe, as hierarquias e as preferências que impõe, o conjunto das condições tácitas de pertencimento [...]" (Bourdieu, 2013, p. 113, grifo do autor). Por mais que se destaque a vivência em espaços tecnologicamente mediados, as dinâmicas sociais ensejam jogos e pressuposições que precisam ser levados em consideração no mundo contemporâneo. Hoje, diferentemente do que se poderia supor em anos anteriores, as dinâmicas ensejadas nestas redes impactam diretamente não apenas a produção de conteúdo nas mídias massivas, mas também a veiculação deste conteúdo.

Exatamente por isso, o estudo das dinâmicas interacionais nesses espaços permite que se visualize novas possibilidades para as TVs, tanto públicas quanto privadas. Este artigo focaliza dois desses espaços (Facebook e YouTube) da TV da Fundação Rádio e Televisão Educativa de Uberlândia (RTU), ligada à Universidade Federal de Uberlândia (UFU) e localizada na cidade de Uberlândia, no estado de Minas Gerais.

\section{TV Universitária de Uberlândia}

Em 1988 foi escriturada a Fundação Rádio e Televisão Educativa de Uberlândia (RTU), uma organização privada sem fins lucrativos, com personalidade jurídica própria e "autonomia administrativa, financeira e patrimonial" $\left(\right.$ RTU, 2020) ${ }^{3}$. Trata-se de uma fundação de apoio à Universidade Federal de Uberlândia (UFU), credenciada pelo Ministério da Educação (MEC) e Ministério da Ciência, Tecnologia, Inovações e Comunicações (MCTIC) desde 2009. Dentre as especificidades contidas no Estatuto que a rege, a Fundação RTU tem como objetivo principal contribuir com a qualidade da educação e da cultura, por meio de programas de rádio e televisão educativas. A TV Universitária de Uberlândia possui grande parte da programação composta por conteúdos da Rede Minas de Televisão ${ }^{4}$ (ex.: Sou 60; Harmonia; Agenda; Jornal Minas; e Meio de Campo) e da TV Cultura ${ }^{5}$ (ex.: Jornal da Cultura; Roda Viva; e Repórter Eco).

\footnotetext{
${ }^{2}$ Informações disponíveis em: http://g1.globo.com/o-brasil-que-eu-quero/. Acesso em: 20 mar. 2018.

${ }^{3}$ Todas as informações desta pesquisa foram retiradas do site da Fundação RTU. Disponível em: http://www.rtu.ufu.br

${ }^{4}$ A Rede Minas de Televisão é uma emissora pública e educativa de Belo Horizonte, sendo considerada a terceira maior do Brasil. Mais informações disponíveis em: http://redeminas.tv/.

${ }^{5}$ A TV Cultura é uma emissora pública e educativa de São Paulo. Informações disponíveis no site oficial da emissora: http://tvcultura.com.br. Acesso em: 21 maio 2020.
} 
Um dos principais conteúdos audiovisuais produzidos pela TV Universitária de Uberlândia era o telejornal TVU Notícias. Este telejornal era veiculado de segunda a sexta-feira, gravado, e tinha como objetivo divulgar conteúdos informativos, culturais e educativos, além de assuntos diretamente relacionados à Universidade Federal de Uberlândia. A partir de 12 de março de 2018, o TVU Notícias foi substituído pelo Telejornal da UFU, transmitido de segunda a sexta, ao vivo, das 19 h às $19 \mathrm{~h} 30$ pelos canais tradicionais do espectro (canal 04 na TV aberta e canal 5 na TV a cabo) e também pelos canais virtuais (Facebook e site oficial da emissora) ${ }^{6}$. Apesar de não mais estar em produção, é importante analisar o TVU Notícias porque grande parte das estratégias inauguradas por ele (como a forma de produzir reportagens e a utilização das mídias sociais) acabou sendo incorporada pela proposta do novo telejornal.

\section{APORTE METODOLÓGICO}

A complexidade implicada no novo cenário contemporâneo, marcado pela aceleração, fluidez de processos e pelo contexto de convergência de mídias, tem imposto cada vez mais desafios aos pesquisadores acadêmicos das mais diversas áreas. Nem sempre os métodos tradicionais de pesquisa conseguem abarcar as muitas faces dos objetos de pesquisa contemporâneos. No caso específico deste estudo, se por um lado existem metodologias específicas para estudos de produção jornalística televisiva (que podem enfocar a narrativa, a estética, a recepção etc), por outro lado fica claro que ainda estamos construindo conhecimentos acerca de como se consome (e também se produz) em um novo ambiente como a web.

É certo que o espectador nunca foi passivo, como apregoavam as chamadas teorias administrativas da Comunicação (Marcondes Filho, 2010), mas também o é o fato de que agora as resultantes de uma divulgação midiática podem ser percebidas de forma muito mais ágil. Em linhas gerais, isso significa dizer que, no que concerne a esta pesquisa, os estudos tradicionais de audiência televisiva não forneceriam dados suficientes para análise. Isto posto, recorreu-se ao aporte metodológico da Altmetria. Originalmente ligada à área de Estudos Métricos da Informação, a Altmetria focaliza a medição da produção científica no contexto da web 2.0 (Priem, Groth, \& Taraborelli, 2012).

A emergência da web 2.0 tem proporcionado cada vez mais acesso às pesquisas acadêmicas por meio de um volume cada vez maior de publicações científicas de acesso aberto. A este cenário, soma-se o fato de que a utilização das mídias sociais virtuais tem se tornado uma tônica cotidiana e, por meio delas, também é possível acessar conteúdos científicos produzidos pela Academia. Desta forma, para além da tradicional contagem de citações, a Altmetria pode desvelar a influência ou impacto de uma atividade científica tanto dentro quanto fora do ambiente acadêmico.

Isso quer dizer que, embora esteja concentrada em medir o impacto acadêmico em ambientes online (Alperin, 2013), os dados altmétricos "podem incluir dados de aplicações gerais e plataformas técnicas. Às vezes, o termo abrange também as referências da mídia massiva, bem como dados de editoras, como visualizações de páginas web e downloads" (Taylor, 2013, tradução nossa ${ }^{7}$ ). Isto posto, fica claro que, de fato, a Altmetria oferece importante contribuição para compreender, avaliar e monitorar o impacto social das pesquisas acadêmicas (Vanti \& Sanz-Casado, 2016).

No que se refere aos indicadores, Vanti e Sanz-Casado (2016) explicam que os indicadores altmétricos se inserem no escopo dos indicadores alternativos, ou seja, aqueles que são considerados não convencionais para a ciência. Torres, Cabezas, e Jiménez (2013) entendem que os indicadores altmétricos devem levar em consideração a interação dos usuários em espaços virtuais como Facebook, Twitter etc com materiais gerados por pesquisadores. Estes usuários, no entanto, podem ou não ser pesquisadores. Novamente, destaca-se aqui o fator repercussão social extramuros. Levando-se em consideração estes aspectos, os indicadores altmétricos podem ser divididos em três grupos, quais sejam: 1 - medidas de repercussão social (número de menções ou citações), 2 - medidas de uso das publicações científicas (quantidade de downloads de materiais científicos ou ainda pelo número de usuários que utilizaram dados de trabalhos científicos em suas referências) e 3 -medidas de qualidade das publicações (número de citações oriundas de avaliação por pares).

Coletar dados altmétricos, no entanto, nem sempre é fácil, justamente porque as fontes são diversas e os públicos bastante distintos. O site Altmetric.com contabiliza conteúdos diversos (tais como notícias em portais, postagens em Facebook, tweets, etc) relacionados a um artigo e oferece uma pontuação (uma espécie de Score Altmétrico). Segundo Araújo (2015, p.100), deve refletir: "I - a visibilidade - quantidade de atenção recebida - em geral, quanto mais pessoas visualizam ou falam sobre um artigo, maior sua pontuação; (ii) a qualidade da atenção local postado e reputação de quem posta". Nesse aspecto, segundo o autor, "uma matéria num portal de notícia

\footnotetext{
${ }^{6}$ Site Oficial da TV Universitária, disponível em: http://www.tvuniversitaria.ufu.br/. Página do Facebook, disponível em: https://www.facebook.com/tvu.uberlandia/. Canal no YouTube, disponível em: https://www.youtube.com/RTUniversitaria.

${ }^{7}$ Tradução livre do original: "[...] also include data from general applications and technical platforms. Sometimes the term also encompasses mass-media references, and data from publishers, such as web page views and PDF downloads". Texto original disponível em: https://www.researchtrends.com/issue-33-june-2013/the-challenges-of-measuring-social-impact-using-altmetrics/. Acesso em: 20 maio 2020 .
} 
conta mais que a de um post no Facebook. Atenção de um pesquisador conta mais do que a atenção de um Twitter bot automatizado"(Araújo, 2015, p. 100).

Apesar de estar baseada na análise de produções oriundas de públicos diversos a partir da interação com conteúdo científico, a Altmetria ainda parte do material tradicional como fonte primária, ou seja, o artigo científico, e não necessariamente do conhecimento científico gerado (do qual o artigo é resultante). A forma escrita de um artigo é apenas uma dentre inúmeras maneiras de apresentação de um conhecimento científico. Numa primeira mirada, ela pode parecer a mais indicada, mas talvez seja apenas aquela com a qual a maior parte dos pesquisadores está familiarizada. Essa discussão é importante porque a produção audiovisual é cada vez maior e já existem fundações de amparo à pesquisa (a exemplo da Fundação de Amparo à Pesquisa do Estado de Minas Gerais - FAPEMIG) que pressupõem, além da apresentação de relatórios finais de pesquisa, também a produção de materiais audiovisuais (também chamado de $\mathrm{PITCH}^{8}$ ) para divulgação dos resultados obtidos.

Compreendendo que a produção telejornalística de uma emissora pública de televisão, notadamente de caráter universitário - como a Televisão Universitária de Uberlândia - se pauta justamente por disseminar conteúdos (muitos deles oriundos de pesquisas desenvolvidas na própria Universidade) para uma audiência diversa daquela da comunidade acadêmica especializada, esta pesquisa assume que o aporte da Altmetria se revela salutar para compreender as nuances desse tipo de produção.

Uma vez que estes materiais são produzidos para a televisão (e só num segundo momento - numa fase que poder-se-ia indicar como pós-exibição televisiva - é que são postados nas demais mídias), utilizou-se, num primeiro momento, o ponto de vista do endereçamento - que, conforme Gomes (2011) faz referência uma metodologia abrangente para o telejornalismo e que articula três pontos de análise: "o jornalismo, a televisão e a recepção televisiva" (Gomes, 2011, p. 18).

Para analisar um telejornal, a autora propõe descrever ou interpretar os seguintes operadores de análise: a apresentação dos mediadores (que são os agentes que fazem o programa), principalmente a dos apresentadores, mas também as dos repórteres e comentaristas; o contexto comunicativo, que compreende emissor e receptor, as condições de espaço e tempo em que a comunicação é feita, e as particularidades na forma de comunicação, cenário e postura do profissional; a organização temática, que implica na escolha de determinadas temáticas e editorias com o intuito de se aproximar de uma audiência específica (?). O modo de endereçamento diz respeito à maneira com que determinado telejornal se relaciona com a audiência, construindo determinados estilos que o identifica e diferencia de outros (Gomes, 2011), e nisto está incluída a confluência com as mídias sociais.

Nesse ponto, uma vez postados no Facebook e no YouTube, esses materiais alcançam uma outra audiência que se expressa de forma distinta. Por esta razão, no segundo momento de análise, optou-se por utilizar o monitoramento - que é, na verdade, uma estratégia de acompanhamento de algo ou alguém. Várias plataformas online, gratuitas e pagas, possibilitam a coleta e interpretação de dados para as mais diversas aplicações. A estratégia de acompanhar as interações dos usuários nas mídias sociais possui várias aplicações, como: relacionamento (um dos primeiros propósitos); identificar reações em relação a produtos, serviços, marcas, pessoas; conhecer demandas para desenvolvimento de produtos; analisar tendências de comportamento; mensuração de público; entre outros (Zandavalle, 2016).

\section{SELEÇÃO DA AMOSTRA E RESULTADOS}

A seleção da amostra para esta pesquisa se deu a partir das temáticas mais abordadas pelo telejornal e com maior número de visualizações no Facebook e YouTube (acima de mil visualizações), por meio do monitoramento dessas mídias, no período de janeiro a junho de $2017^{9}$. A plataforma utilizada para auxiliar no monitoramento foi a versão gratuita da Fanpage Karma; e tal processo foi realizado até o dia 20 de março de 2018.

No último dia de coleta, 20 de março de 2018, a mídia social Facebook da emissora contava com 7.651 inscritos e o canal do YouTube com 4.732 inscritos. A primeira postagem de vídeos no Facebook pela TV Universitária de Uberlândia foi em junho de 2015 e no YouTube, em dezembro de 2015. Desde então, as páginas das mídias sociais são abastecidas com as reportagens que foram veiculadas no telejornal TVU Notícias completo e, agora pelo Telejornal da UFU, com transmissões ao vivo pelo Facebook.

A partir desta quantificação, foram selecionados os vídeos com mais de 10 mil visualizações no Facebook e, destes, os três primeiros colocados foram escolhidos para a análise mais detalhada concernente às estratégias de endereçamento utilizadas. Aqui, é salutar frisar que a análise não parte de um artigo científico específico para

\footnotetext{
${ }^{8}$ De acordo com o site oficial da FAPEMIG, PITCH "é um vídeo curto, simples e direto, que pode ser feito por celular ou câmera comum, no qual o pesquisador apresentará o resultado, produto, processo ou serviço, em uma linguagem acessível a qualquer cidadão. A linguagem devem conter termos simples e de preferência, substituir a linguagem técnico-científica (quando possível) para que também abranja um público alvo fora do âmbito acadêmico. O pitch permite expor ideias, produtos ou tecnologias de maneira simples, rápida e palatável". Informação disponível em: https://fapemig.br/pt/. Acesso em: 21 maio 2020.

${ }^{9} \mathrm{O}$ período escolhido se deve ao fato de duas das autoras do presente artigo terem trabalhado diretamente na TV Universitária de Uberlândia, especificamente na produção do telejornal TVU Notícias, com orientação docente.
} 


\begin{tabular}{|c|c|c|c|c|}
\hline Título & Visualizações & Compartilhamentos & Comentários & Reações \\
\hline Tradição caseira mineira (27/04/17) & 21.306 & 246 & 8 & 51 \\
\hline $\begin{array}{l}\text { Saiba mais sobre a Ame - amiotrofia } \\
\text { muscular espinhal }(04 / 04 / 17)\end{array}$ & 17.079 & 254 & 33 & 180 \\
\hline $\begin{array}{l}\text { Importância das abelhas é pesquisa } \\
\text { na Universidade Federal de Uberlândia } \\
\text { (01/05/17) }\end{array}$ & 15.618 & 363 & 13 & 107 \\
\hline Osteoartrite no joelho $(08 / 06 / 2017)$ & 14.361 & 110 & 15 & 112 \\
\hline $\begin{array}{l}\text { Uberlândia agora possui escola de pro- } \\
\text { gramação e robótica }(07 / 03 / 17)\end{array}$ & 14.229 & 239 & 58 & 136 \\
\hline $\begin{array}{l}\text { Cuidados com os dentes dos pequeninos } \\
(24 / 02 / 17)\end{array}$ & 10.115 & 51 & 4 & 33 \\
\hline
\end{tabular}

Tabela 1. Interações do público com os vídeos

realizar a coleta altmétrica, mas antes busca compreender quais são os conteúdos mais acessados e de que forma são produzidos.

\begin{tabular}{lccccccc}
\hline & \multicolumn{7}{c}{ Reações } \\
\hline Título & Curtir & Amei & Engraçado & Surpresa & Triste & Raiva \\
\hline Tradição caseira mineira (27/04/17) & 46 & 5 & 0 & 0 & 0 & 0 \\
\hline $\begin{array}{l}\text { Saiba mais sobre a Ame - amiotrofia muscular } \\
\text { espinhal (04/04/17) }\end{array}$ & 160 & 20 & 0 & 3 & 0 & 0 \\
\hline $\begin{array}{l}\text { Importância das abelhas é pesquisa na Univer- } \\
\text { sidade Federal de Uberlândia (01/05/17) }\end{array}$ & 87 & 20 & 0 & 0 & 0 & 0 \\
\hline
\end{tabular}

Tabela 2. Detalhamento das reações

A apresentação dos dados quantitativos também auxilia na investigação sobre a organização temática, averiguando se há variedade de assuntos e valorização do interesse público. A partir desse levantamento, passou-se para um maior detalhamento da interação do público com estes materiais. De acordo com Thelwall, Haustein, Larivière, e Sugimoto (2013), a coleta de dados altmétricos em espaços da web social, tais como Facebook, por exemplo, implica em compreender as formas interacionais possíveis nestes espaços: compartilhamentos, curtidas, retweets, comentários, reações etc.

Com base nos dados obtidos na Tabela 1, e tendo em vista que interessa à TV Pública fazer com seus vídeos cheguem a um número maior de cidadãos, selecionou-se os três vídeos que atingiram o maior número de compartilhamentos para a confecção da Tabela 2. Nela, é possível visualizar o detalhamento das reações das pessoas diante destes vídeos.

Estas formas de expressão online devem ser consideradas como importantes indicativos da divulgação de pesquisas científicas (Torres, Cabezas \& Jiménez, 2013). Uma vez que tais expressões ainda se colocam apenas como indicativos, torna-se importante aprofundar o detalhamento acerca do conteúdo audiovisual a ela associado. Desta forma, na sequência, selecionaram-se os três vídeos mais visualizados no Facebook naquele período e as formas de interações do público (compartilhamento, comentários etc.).

\section{Estratégias de endereçamento}

O estudo das estratégias de endereçamento em três reportagens com maior número de visualizações no Facebook se deu segundo as seguintes temáticas: cultura, saúde e pesquisa da Universidade Federal de Uberlândia, respectivamente. Elas serão analisadas em três aspectos principais: apresentação dos mediadores, contexto comunicativo e atribuições do jornalismo. Posteriormente, será abordada a organização temática, tanto dos três objetos de análise quanto da programação entre os meses pontuados no decorrer do artigo. De forma direta e indireta serão elencados aspectos que estão em funcionamento e aqueles que precisam ser adaptados para uma comunicação pública educativa mais eficiente, tanto na televisão quanto nas mídias sociais. 
Reportagem 1

\section{Tradição mineira caseira}

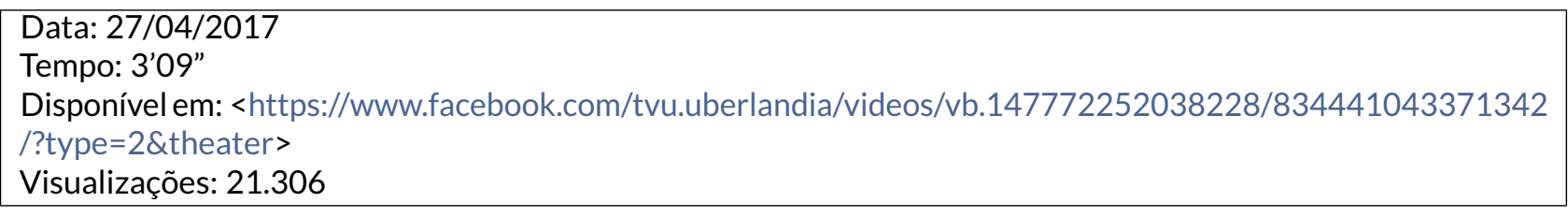

A reportagem com maior número de visualizações no Facebook entre os meses de janeiro e junho de 2017 versa sobre um assunto culinário, uma temática mais social, pois envolve não somente a refeição, mas também as relações sociais que são propiciadas ao redor da mesa. A chamada no Facebook dá uma noção do que será abordado na reportagem; "Estamos no interior de Minas e por aqui é forte a tradição dos doces caseiros e comidas típicas mais calóricas. Em uma simples visita, está ele: o cafezinho com um quitute mineiro. Difícil resistir, mas não dá pra descuidar da saúde". Neste caso, também é retratado um aspecto cultural muito presente no interior de Minas Gerais, que é a hospitalidade e a vontade de agradar as pessoas, propiciando um momento de tranquilidade, a tradição de oferecer um "cafezinho", quase sempre acompanhado de um doce, que é o tema norteador desta matéria.

A reportagem aborda três aspectos diferentes: a questão da cultura e tradição passada de pais para filhos; a variedade de doces e o modo de preparo; e o aspecto nutricional no consumo de açúcares. A abordagem visa o interesse de empresários do ramo de doces artesanais, daqueles que gostam de se deliciar com as iguarias e os que buscam o consumo de açúcar de forma moderada; mas, sobretudo, direciona-se àqueles que apreciam a cultura, a memória aos aspectos tradicionais e o preparo caseiro. A apresentação da repórter, bem como o contexto comunicativo, tem o intuito de se aproximar do telespectador. A escolha por uma linguagem mais leve condiz com o assunto tratado: a questão de uma cultura que remete ao interior, à fazenda e que, por inúmeros motivos, é rememorada na cidade.

A reportagem busca valorizar o interesse público, além de assegurar a pluralidade de informações. Por tudo isso, pode-se confirmar a relevância social, justamente por ser um assunto amplamente social, que é a cultura em conjunto com a culinária. O fato de a reportagem estar disponibilizada nas redes sociais também contribui para o alcance de maior número de pessoas, incluindo o público consumidor de doces artesanais. O vídeo foi amplamente compartilhado pela página da emissora no Facebook, o que possibilitou a visualização da reportagem por várias pessoas que não teriam acesso pelo canal televisivo. A opção de compartilhar o conteúdo é um dos fatos que corroboram a importância deste recurso no intuito de atrair novos espectadores, mesmo que o formato da reportagem não seja desenvolvido especificamente para a web.

Reportagem 2

Saiba mais sobre a AME - amiotrofia muscular espinhal

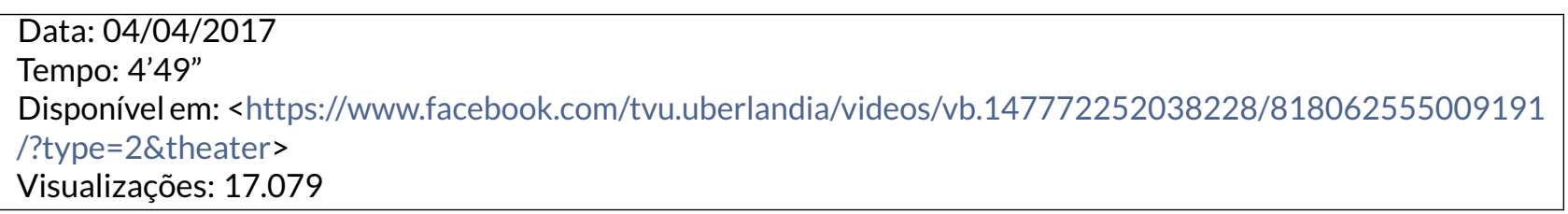

A reportagem em segunda colocação no número de visualizações diz respeito a uma doença degenerativa, a Amiotrofia Muscular Espinhal. Assuntos relacionados à saúde, bem-estar, doenças, tratamentos médicos, dentre outros nesta área, são amplamente abordados nos programas da TV Universitária, por abarcarem um público amplo.

Novamente, a chamada no Facebook conta o assunto a ser tratado na reportagem; "Você já ouviu falar em amiotrofia muscular espinhal, mais conhecida como Ame? É uma doença genética e degenerativa que até ficou mais conhecida por alguns nos últimos dias por conta do Joaquim, um bebê que tem a doença. Os pais fizeram uma campanha na internet para arrecadar dinheiro para o tratamento. Na reportagem a seguir, vamos saber o que é essa doença e também conhecer a história da Íris". Neste caso, já é apontado que será contada a história de uma pessoa, mais especificamente de uma criança.

Esta reportagem aborda quatro aspectos diferentes: a doença e seus subtipos; a história do diagnóstico de uma personagem; o espaço criado pelos pais da personagem para fisioterapia intensiva na metodologia PediaSuit; e o protótipo de uma gaiola criado pelo pai skatista para que a filha pudesse andar de skate, bem como outras crianças que tenham a doença. O público a ser contemplado é, basicamente, composto por pessoas que tenham interesse em conhecer ou estudar sobre a doença, e aquelas que convivem direta e indiretamente com o problema.

Estas pessoas, contudo, estão espalhadas por todo o país, então a publicação da reportagem nas mídias sociais garante a disseminação em âmbito nacional e, até mesmo, mundial, bastando que se tenha uma rede de internet 
e uma conta no Facebook. A apresentação da repórter, assim como o contexto comunicativo, tem o objetivo de informar e sensibilizar os telespectadores. A história de Íris não deixa de ser comovente, por todos os problemas enfrentados com tão pouca idade e por toda a força de vontade apresentada pelos pais em ajudar não somente a filha, mas também inúmeras outras pessoas que convivem com a doença, o que contribui ainda mais para o grande número de pessoas interessadas em sua história.

A linguagem utilizada é formal, o que condiz com o assunto, mas de fácil entendimento e a reportagem, em geral, valoriza o interesse público e assegura a pluralidade de informações. Apesar de não ser um vídeo feito propriamente para a web e para as mídias sociais, o vídeo teve muitos compartilhamentos de pessoas diversas, o que contribui significativamente para o número de visualizações. Além disso, na maioria das reações e comentários dos internautas, a história de vida de Íris e o projeto Viva Íris foram destaques; e palavras como "família", "esperança" e "amor" estão entre as mais citadas.

Reportagem 3

Importância das abelhas é pesquisa na Universidade Federal de Uberlândia

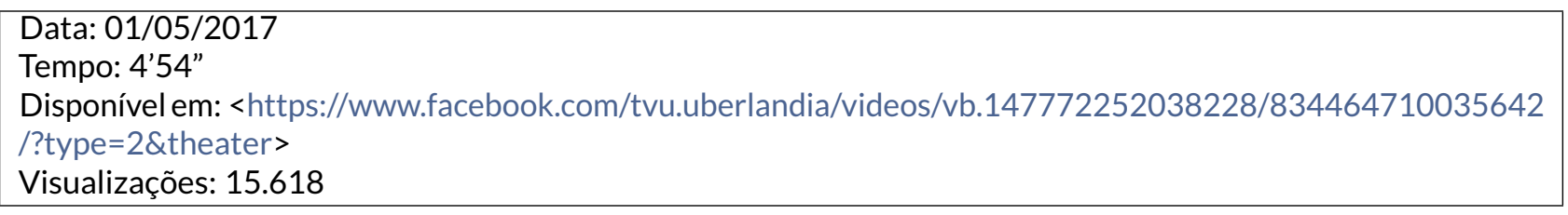

A terceira reportagem em análise possui uma temática científica mais evidente, tratando de estudos científicos desenvolvidos no Instituto de Biologia da Universidade Federal de Uberlândia (UFU). O tema geral da reportagem é a pesquisa das abelhas, o que já é apontado na chamada do Facebook: "As abelhas desenvolvem o importante papel da polinização e algumas espécies produzem mel. Para pensar e descobrir cientificamente a importância real das abelhas, são realizadas várias pesquisas na Universidade Federal de Uberlândia". A repórter, neste caso, atua como uma "tradutora" da linguagem científica.

Esta reportagem, apesar de ser científica e aparentemente voltada para um público específico de estudantes e pesquisadores, aborda três aspectos diferentes: o trabalho científico desenvolvido com abelhas do Cerrado no laboratório da UFU; a importância das abelhas no equilíbrio ambiental e na produtividade de plantios; e o trabalho de campo desenvolvido com estudantes de escolas municipais, trabalhando a questão educativa. É a exemplificação prática das três vertentes de estudos apontados na sonora da coordenadora e docente do Instituto de Biologia (vertentes comportamentais, educativas e em trabalhos de extensão).

Sendo assim, vários públicos são contemplados. A abordagem busca o interesse de estudantes e pesquisadores, produtores rurais e pessoas interessadas em assuntos socioambientais. A apresentação da repórter, assim como o contexto comunicativo, busca aproximar os telespectadores do assunto. A linguagem leve traduz a abordagem científica dos estudos, o que possibilita um fácil entendimento das pesquisas e dos objetivos pretendidos pelos pesquisadores da universidade. Além disso, a reportagem assegura, novamente, a pluralidade de informações e busca valorizar o interesse público.

\section{CONSIDERAÇÕES FINAIS}

Entre os meses de janeiro e junho de 2017, de maneira geral, os principais assuntos abordados foram relacionadas à universidade (projetos científicos, publicação de livros, eventos, lançamento de editais, cursos), questões de saúde (alimentação, doenças em geral e prevenção, benefícios de exercícios físicos), prefeitura municipal (projetos, coletivas de imprensa, saúde pública, impostos e tarifas), Uberlândia e região (projetos de organizações não governamentais, comércio, esporte, cursos) e interesses gerais. Esta organização temática aponta para um público-alvo que envolve não somente universitários e pesquisadores, mas todos que se envolvem e interessam por reportagens educativas.

Conforme os dados apresentados nas tabelas 1 e 2, as temáticas que atraíram a atenção do público nas mídias sociais foram: saúde, descobertas científicas e eventos da UFU, inovação tecnológica, cultura, e esportes. Um ponto interessante a ser ressaltado é que a linguagem utilizada, levando em consideração os três vídeos de maior visualização, é formal e leve. Por isso o uso das mídias sociais para difundir esse material é tão importante, pois abarca pessoas que se interessam pelas temáticas educativas, mas não necessariamente têm acesso ao conteúdo produzido para a televisão. O que se pretende ressaltar é que a rede social tem potencial de atrair públicos diversos e isso é o que realmente chama a atenção de uma pessoa que opta por assistir uma reportagem no Facebook.

Desta forma, a opção de publicar as reportagens isoladamente é um aspecto positivo, visto que as publicações do telejornal completo são as de menor número de visualizações. Apesar de o conteúdo não ser produzido especificamente para as mídias sociais, os dados apresentados nas tabelas mostram que estas têm um grande 
potencial de abarcar mais espectadores - não necessariamente um grupo específico, mas pessoas diversas que se interessam por assuntos também diversos. Assim, o telejornal da Fundação RTU - UFU - traduzido por meio do TVU Notícias - coloca-se como um espaço de exposição jornalística de qualidade, voltada ao interesse público.

No TVU Notícias, os principais assuntos abordados no período de análise valorizaram o interesse público. Entretanto, um ponto importante é a falta de reuniões de pauta, o que deixa a escolha dos assuntos apenas para a visão principal do editor-chefe ${ }^{10}$. Assim, não há variedade de ideias e opiniões. Uma reunião semanal ampliaria o leque de informações discutidas e, tendo em vista que grande parte das matérias não tem caráter factual, possibilitaria um aprofundamento destas, considerando que o foco principal das reportagens é fazer o público refletir.

Uma televisão pública e educativa deve ser pautada por assuntos aprofundados: como não há concorrência com a televisão comercial, o foco deve ser a qualidade no conteúdo, justamente o que a diferencia. A partir desta ponderação, observa-se que seria importante que as reportagens contemplassem várias vertentes do mesmo assunto, entrevistando quantas pessoas fossem necessárias para compreensão do tema. A televisão educativa comporta reportagens com mais minutos de duração em relação às reportagens da televisão comercial. Desta forma, o tempo do telejornal utilizado em duas reportagens poderia ser cedido para uma reportagem mais aprofundada, tendo em vista que as reportagens aqui destacadas têm, em média, menos de cinco minutos. O endereçamento, por sua vez, está diretamente ligado à forma como o material é produzido e como ele é acessado pelo telespectador. Assim, quanto mais formas de disseminar o conteúdo produzido, maiores as chances de que ele chegue a públicos diversos em locais distintos.

Finalmente, é importante destacar que, apesar das limitações do estudo (tais como recorte temporal e número de reportagens analisadas em profundidade), os resultados incidem em dois aspectos: por um lado indica que a produção audiovisual jornalística - quer seja na televisão tradicional quer seja nas mídias sociais - tem muito a aportar à divulgação científica (e vice-versa) e, por outro lado, destaca que a televisão pública ainda se coloca como um espaço privilegiado desses conteúdos.

\footnotetext{
${ }^{10}$ Observações feitas por duas das autoras do artigo. Ambas foram estagiárias da Fundação RTU e participaram ativamente da produção do TVU Notícias por um ano.
} 


\section{REFERÊNCIAS}

Alperin, J. P. (2013). Ask not what altmetrics can do for you, but what altmetrics can do for developing countries. Bulletin of the American Society for Information Science and Technology, 39(4), 18-21.

Araújo, R. F. (2015). Mídias sociais e comunicação científica: análise altmétrica em artigos de periódicos da ciência da informação. Em Questão, 21(1), 96-109.

Bourdieu, P. (2013). Capital simbólico e classes sociais. Novos Estudos - CEBRAP(96), 105-115. doi: 10.1590/s010133002013000200008

Bruno, F. (2006). Estética do flagrante: controle e prazer nos dispositivos de vigilância contemporâneos. Revista Cinética. Recuperado de http://www.revistacinetica.com.br/ cep/fernanda_bruno.htm

Bucci, E. (2013). Sobre a independência das emissoras públicas no brasil. Revista Eptic Online, 15(2), 121-136. Recuperado de https://seer.ufs.br/index.php/eptic/article/ view $/ 944 / 816$

Carrato, A. (2013). Uma história da TV Pública brasileira (Tese de Doutorado, Faculdade de Comunicação, Universidade de Brasília, Brasília). Recuperado de https://repositorio.unb.br/bitstream/10482/15462/ 1/2013_AngelaMariaCarratoDiniz.pdf

Decreto-Lei n. 236. (1967). Complementa e modifica a Lei número 4.117 de 27 de agosto de 1962. Recuperado de http://www.planalto.gov.br/ccivil_03/decreto-lei/ Del0236.htm (de 28 de fevereiro de 1967)

Gomes, I. M. M. (2011). Gênero televisivo e modo de endereçamento no telejornalismo. EDUFBA. doi: $10.7476 / 9788523211998$

Jambeiro, O. (2012). A tv no brasil do século xx. Edufba. Recuperado de http://www.planalto.gov.br/ccivil_03/leis/ L4117.htm (Lei n. 4.117, de 27 Agosto de 1962. Institui o Código Brasileiro de Telecomunicaçães)

Lei n. 4.117. (1962). Institui o Código Brasileiro de Telecomunicações. Recuperado de http://www.planalto.gov.br/ ccivil_03/leis/L4117.htm (de 27 Agosto de 1962)

Lima, F. B., Priolli, G., \& Machado, A. (1985). Televisão e vídeo. Rio de Janeiro: Zahar.

Lins, F. (2015). 1948: O pioneirismo da televisão em Juiz de Fora. Revista Brasileira de História da Midia (RBHM), $1(2)$.

Marcondes Filho, C. (2010). O princípio da razão durante: o conceito de comunicação e a espistemologia metapórica: nova teoria da comunicação iii: tomo v. São Paulo: Paulus.

Mattos, S. (2002). História da Televisão Brasileira-Uma Visão Econômica. Petrópolis: Vozes.

Meso, K., Agirreakzuenaga, I., \& Larrondo, A. (2015). Active audiences and journalism. Servicio Editorial de la Universidad del País Vasco.

Nazareno, C. (2007). A implantação da TV pública no Brasil. Brasília: Consultoria Legislativa.

Paternostro, V. I. (2006). O texto na TV: manual de telejornalismo (2a. ed.). Rio de Janeiro: Elsevier.

Pieranti, O. P., \& Fernandes, E. M. d. N. B. (2017). Radiodifusão pública? A programação das emissoras de TV educativa no Brasil. Revista Eptic, 19(3), 69-84.

Prevedello, C. F. (2017). 50 anos de TVs universitárias no
Brasil. Revista Eptic, 19(3), 102-114.

Priem, J., Groth, P., \& Taraborelli, D. (2012). The altmetrics collection. PloS one, 7(11).

Recuero, R. (2009). Mídias sociais na Internet (2a. ed.). Porto Alegre: Sulina.

Recuero, R. (2012). O Capital Social em Rede: Como as redes sociais na Internet estão gerando novas formas de capital social. Contemporânea: Revista de Comunicação e Cultura, $10(3)$, 597-617.

Santana, J. d. L., Dias, R., Muniz, E. L., \& Gomes, V. M. L. R. (2017). Stj notícias como tv pública: a participação cidadã da audiência em relação ao processo de produção de notícia. Revista Eptic, 19(3), 115-136.

Santos, V. M. d., Santos, A. C. O., Marinho Jr., I. A., \& Santos, J. P. O. (2016). Cultura e Educação nas TVs do campo público: reflexães à luz da programação televisiva da Fundação RTU. In N. M. W. Santos \& A. L. C. Moraes (Eds.), TVS Públicas: memórias de arquivos audiovisuais (p. 255-267). São Leopoldo: Oikos.

Silva, N. P. (2016). Mediação e arte: produtos e consumo de produtos culturais na TV pública. In N. M. W. Santos \& A. L. C. Moraes (Eds.), TVS Públicas: memórias de arquivos audiovisuais (p. 54-64). São Leopoldo: Oikos.

Stevanim, L. F. F. (2017). Democratização da comunicação e sistema público de mídia: um olhar a partir dos movimentos sociais. Revista Eptic, 19(3), 85-101.

Thelwall, M., Haustein, S., Larivière, V., \& Sugimoto, C. R. (2013). Do altmetrics work? twitter and ten other social web services. PloS one, 8(5), e64841. doi: 10.1371/journal.pone.0064841

Torres, D., Cabezas, A., \& Jiménez, E. (2013). Altmetrics: nuevos indicadores para la comunicación científica en la web 2.0. Comunicar: Revista Científica de Educomunicación, 21 (41), 53-60.

Traquina, N. (2004). Teorias do Jornalismo. Florianópolis: Insular.

Vanti, N., \& Sanz-Casado, E. (2016). Altmetria: a métrica social a serviço de uma ciência mais democrática. Transinformação, 28(3), 349-358.

Zandavalle, A. C. (2016). O mercado de inteligência de mídias sociais. In T. Silva \& M. Stabile (Eds.), Monitoramento e pesquisa em mídias sociais: metodologias, aplicaçães e inovaçães (p. 11-27). São Paulo: IBPAD.

Como citar este artigo (APA):

Santos, V. M., Oliveira, C. R., Freitas, C. F. \& Vieira, V. (2019). O audiovisual jornalístico da TV Pública nas mídias sociais: possibilidades e desafios para a divulgação científica. AtoZ: novas práticas em informação e conhecimento, 8(2), 28 - 38. Recuperado de: http://dx.doi.org/10.5380/atoz.v8i2.69923 